\title{
Lipid metabolism in riboflavin-deficient rats
}

\section{Mitochondrial fatty acid oxidation and the microsomal desaturation pathway}

\author{
By S. E. OLPIN AND C. J. BATES* \\ Dunn Nutrition Unit, University of Cambridge and Medical Research Council, \\ Cambridge CB4 $1 X J$
}

(Received 1 September 1981 - Accepted 4 December 1981)

1. Oxygen consumption was measured by means of an $\mathrm{O}_{2}$ electrode in mitochondrial suspensions from riboflavin-deficient and pair-fed control rats, using six different substrates. Whereas consumption of $\mathrm{O}_{2}$ by glutamate was only slightly depressed in mitochondria from deficient animals, the consumption of $\mathrm{O}_{2}$ by hexanoate and by palmitoyl-L-carnitine was depressed to approximately half the control value: a highly significant difference. A comparable magnitude of depression was observed for stearoyl-, oleoyl-, and linoleoyl-L-carnitine. There were no major or consistent differences between groups of animals receiving two different types, and two different levels, of fat in their diet.

2. The activity of acyl coenzyme A dehydrogenase (EC 1.3.99.3) in hepatic mitochondrial fragments, measured by cytochrome $c$ reduction with palmitoyl-coenzyme $A$ as substrate, and expressed as maximum velocity $\left(V_{\max }\right)$ with respect to phenazine methosulphate, was also reduced to approximately half the control value in deficient animals.

3. In hepatic microsomes, cytochrome $b_{5}$ reductase $(E C 1.6 .2 .2)$ activity was unaffected by riboflavin deficiency, although NADPH-cytochrome $c$ reductase $(E C$ 1 6.2 .4$)$ and microsomal flavin content were diminished to approximately half the control values. Acyl $\operatorname{CoA}(\Delta 9)$ desaturase activity $(E C 1.14 .99 .5)$ was virtually identical in deficient, pair-fed, and ad lib.-fed control groups.

4. It is concluded that the depression of mitochondrial $\beta$-oxidation of fatty acids which is observed in riboflavin-deficient animals is not a secondary result of inanition, and may account for the observed changes in fatty acid profiles of triglycerides and phospholipids. Failure of the microsomal fatty acid desaturation system is less likely to be a major consequence of riboflavin deficiency.

Riboflavin deficiency is associated with a major impairment of lipid economy (Olpin \& Bates, 1982). Studies by Hoppel \& Tandler (1975) on mice, and by Hoppel et al. (1979) on rats have suggested that mitochondrial fatty acid $\beta$-oxidation, which involves a sequence of three flavin-dependent enzymes in the initial rate-limiting dehydrogenase reaction, may be especialiy sensitive to variations in riboflavin status. This could perhaps explain some of the physiological abnormalities, such as hepatic lipid accumulation and the deleterious effects of high-fat diets, which are seen in deficient animals.

On the other hand, some of the characteristics of riboflavin deficiency: notably the accumulation of the fatty acid 18:2 at the expense of $20: 4$ in liver phospholipids, might be interpreted as evidence for a lesion in fatty acid desaturation : either at the flavin-dependent microsomal NADH cytochrome $b_{5}$ reductase $(E C 1.6 .2 .2)$ which channels electrons into fatty acid desaturases, or at some other component of the desaturase systems.

The purpose of the present study was first to examine in greater detail the proposal that mitochondrial fatty acid oxidation is impaired in riboflavin deficiency, and secondly to measure microsomal function in relation to fatty acid desaturation.

MATERIALS AND METHODS

Chemicals

$\left[1-^{14} \mathrm{C}\right]$ stearic acid, specific activity $56.5 \mathrm{mCi} / \mathrm{mmol}$ was obtained from The Radiochemical Centre, Amersham, Bucks. Stearoyl-DL-carnitine chloride, oleoyl-DL-carnitine chloride and 
linoleoyl-DL-carnitine chloride were obtained from PL Biochemicals Inc., Wisconsin. All other biochemicals were obtained from Sigma; the bovine serum albumin (BSA) used was essentially fatty acid-free.

\section{Animals and diets}

Female weanling Norwegian hooded rats were used throughout, and were housed and fed as described previously (Olpin \& Bates, 1982); neck collars being used to prevent coprophagy. The mean starting body-weights and the duration of each experiment are given in Tables $1-4$.

\section{Tissue preparation}

Isolation of mitochondria for fatty acid oxidation and acyl CoA dehydrogenase measurements. Animals were anaesthetized with diethyl ether and exsanguinated. Liver samples $(5 \mathrm{~g})$ were then homogenized, in a Potter-Elvehjem homogenizer, in $20 \mathrm{ml}$ of a buffer ( $\mathrm{pH} \mathrm{7.4})$ containing sucrose $0.25 \mathrm{~mol} / 1$, Tris (hydroxymethyl methylamine) chloride $0.05 \mathrm{~mol} / \mathrm{l}$, ethyleneglycol bis ( $\beta$-aminoethyl ether) $N, N$ tetraacetic acid (EGTA) $10^{-3} \mathrm{~mol} / 1$, at $0^{\circ}$. The homogenates were diluted to a tissue concentration of $100 \mathrm{~g} / \mathrm{l}$ and centrifuged at $700 \mathrm{~g}$ for $10 \mathrm{~min}$ to remove nuclei, unbroken cells, and cell debris. Mitochondria were then isolated from the supernatant layers by centrifugation at $6000 \mathrm{~g}$ for $10 \mathrm{~min}$, the pellets were washed by resuspension in a further $20 \mathrm{ml}$ buffer, centrifugation, and resuspension at approximately $10 \mathrm{mg}$ protein $/ \mathrm{ml}$.

Isolation of microsomes for the assay of $N A D H$ cytochrome $\mathrm{b}_{5}$ reductase (EC 1.6.2.2) and NADPH cytochrome c reductase (EC 1.6.2.4). The postmitochondrial supernatant fractions were centrifuged at $105000 \mathrm{~g}$ for $30 \mathrm{~min}$, the resulting pellets were washed by resuspension in phosphate-buffered saline ( $9 \mathrm{~g}$ sodium chloride $/ \mathrm{l}), \mathrm{pH} 7 \cdot 4$, recentrifuged, and suspended in approximately $1 \mathrm{ml}$ phosphate-buffered saline. They were diluted $(1: 50$, $\mathrm{v} / \mathrm{v}$ ) in a solution containing $20 \mathrm{ml}$ Triton $\mathrm{X}-100$ and 0.1 mol sodium phosphate $/ 1, \mathrm{pH} 7 \cdot 7$, to yield a soluble enzyme preparation.

Isolation of microsomes for the assay of acyl $\operatorname{CoA}(\Delta 9)$ desaturase (EC 1 14 .99.5). Liver samples were homogenized in a Potter-Elvehjem homogenizer in a buffer, $\mathrm{pH} 7 \cdot 4$, at $0^{\circ}$ containing $0.3 \mathrm{~mol}$ sucrose $/ 1$ and $0.2 \mathrm{~mol}$ sodium phosphate $/ 1(2 \mathrm{ml} / \mathrm{g}$ fresh liver $)$. These homogenates were centrifuged at $15000 \mathrm{~g}$ for $30 \mathrm{~min}$ and the resulting supernatant fractions were further centrifuged at $100000 \mathrm{~g}$ for $60 \mathrm{~min}$. The microsomal pellets thus obtained were resuspended in the same buffer $(0.5 \mathrm{ml} / \mathrm{g}$ original liver weight).

\section{$\mathrm{O}_{2}$ consumption by mitochondria}

A Clarke-type $\mathrm{O}_{2}$ electrode was used (Rank Bros, Bottisham, Cambridge). The incubation medium, pH 7.0, contained/1: potassium chloride $0.08 \mathrm{~mol}$, morpholino propane sulphonic acid (MOPS) $0.05 \mathrm{~mol}$, sodium phosphate $5 \times 10^{-3} \mathrm{~mol}$, EGTA $10^{-3} \mathrm{~mol}$, bovine serum albumin $1 \mathrm{~g}$. The operating temperature was $30^{\circ}$ and the volume $1.5 \mathrm{ml}$.

Endogenous mitochondrial substrates were first depleted by addition of small amounts of ADP until no further $\mathrm{O}_{2}$ uptake was observed. ADP $(2 \cdot 3 \mu \mathrm{mol})$ was then added and state-3 respiration (Chance \& Williams, 1955) was initiated by addition of substrate.

Final substrate concentrations were (mol/1): L-glutamate $10^{-2}$, hexanoate $4 \times 10^{-4}$ plus L-malate $2 \times 10^{-3}$, palmitoyl-L-carnitine $4 \times 10^{-5}$ plus L-malate $2 \times 10^{-3}$, stearoyl-L-carnitine $4 \times 10^{-5}$ plus L-malate $2 \times 10^{-3}$, oleoyl-L-carnitine $4 \times 10^{-5}$ plus L-malate $2 \times 10^{-3}$ linoleoylL-carnitine $4 \times 10^{-5}$ plus L-malate $2 \times 10^{-3}$. The concentration of mitochondrial protein in the incubating medium was $1-2 \mathrm{mg} / \mathrm{ml}$.

\section{Enzyme assays}

Acyl CoA dehydrogenase (EC 1.3.99.3) in mitochondrial fragments. Mitochondrial fragments were prepared by addition of cholic acid, $1 \mathrm{~g} / 1$ sodium phosphate buffer $(0 \cdot 05 \mathrm{~mol} / 1)$ $\mathrm{pH} 7 \cdot 4$. Acyl CoA dehydrogenase activity was then determined essentially by the methods 
of Hauge (1956) and Hoskins (1969) in a $1.0 \mathrm{ml}$ reaction mixture, $\mathrm{pH} 7.2$ at $30^{\circ}$, containing $(\mathrm{mol} / \mathrm{l})$ : phosphate buffer 0.034 , potassium cyanide $1.5 \times 10^{-3}$, cytochrome $c 1.5 \times 10^{-4}$, rotenone $3.75 \times 10^{-6}$ and phenazine methosulphate (PMS) at three different concentrations $(0.05,0 \cdot 1$ and $0 \cdot 2 \mathrm{~g} / \mathrm{l})$. The enzyme preparation consisted of approximately $40 \mu \mathrm{g}$ mitochondrial protein, and the substrates, added last, were palmitoyl CoA or stearoyl CoA $\left(5 \times 10^{-5} \mathrm{~mol} / \mathrm{l}\right)$. The rate of increase of optical density was followed continuously for $3 \mathrm{~min}$ at $550 \mathrm{~nm}$ in a Pye Unicam SP 1800 recording spectrophotometer. The difference between the molar extinction coefficients of cytochrome $c$ in the oxidized and reduced states was used to calculate the rate of reaction for each concentration of PMS, which was then used to construct a double reciprocal plot and to obtain the maximum velocity with respect to PMS and the Michaelis constant (PMS) for each preparation. This procedure was used in order to overcome the problem of contamination of enzyme with electron-transferring flavoprotein (ETF), which diverts some of the electrons away from PMS, especially at low concentrations of the latter.

NADPH-cytochrome c reductase (EC 1.6.2.4) in microsomal extracts. The incubation medium, $\mathrm{pH} 7.7$ at $25^{\circ}$ contained (mol/l): potassium phosphate buffer 0.3 , NADPH $10^{-4}$ and cytochrome $c 4 \times 10^{-5}$ in a final volume of $1.0 \mathrm{ml}$ (Phillips \& Langdon, 1962). The reaction was started by addition of $40 \mu \mathrm{l}$ Triton-treated microsomal extract, and the change in optical density was followed for $2-5 \min$ at $550 \mathrm{~nm}$.

$N A D H$-cytochrome $b_{5}$ reductase (EC 1.6.2.2) in microsomal extracts. The incubation medium, $\mathrm{pH} 7.7$ at $25^{\circ}$ contained (mol/l): potassium phosphate buffer 0.08 , potassium ferricyanide $10^{-3}$, in a final volume of $1.0 \mathrm{ml}$ (Mihara \& Sato, 1978). The reaction was started by addition of 20 or $40 \mu \mathrm{l}$ Triton-treated microsomal extract and the change in optical density was followed for $5 \mathrm{~min}$ at $420 \mathrm{~nm}$.

Acyl CoA $(\Delta 9)$ desaturase (EC 1.14 .99 .5$)$ in intact microsomes. $\left[1{ }^{-14} \mathrm{C}\right]$ stearic acid bound to BSA was prepared by mixing $177 \mathrm{nmol}(10 \mu \mathrm{Ci})\left[1^{-14} \mathrm{C}\right]$ stearic acid with $355 \mathrm{nmol}$ unlabelled stearic acid in $100 \mu \mathrm{l}$ methanol containing potassium hydroxide $(0.05 \mathrm{~mol} / \mathrm{l})$. A further $500 \mu 1$ of the methanolic potassium hydroxide was added, the methanol was removed in a stream of nitrogen, and $250 \mu \mathrm{l}$ of an aqueous solution of BSA $(4 \cdot 2 \mathrm{~g} / 1)$ was added.

A solution, $\mathrm{pH} 7 \cdot 0$, containing (mol/1): potassium phosphate 1 , magnesium chloride $0 \cdot 08$, EDTA 0.01 , was mixed with NADH (final concentration $3.0 \times 10^{-3} \mathrm{~mol} / \mathrm{l}$ ) and CoA (final concentration $\left.1.5 \times 10^{-3} \mathrm{~mol} / 1\right)$. The following: $0.1 \mathrm{ml}$ of this solution, $0.1 \mathrm{ml}$ adenosine triphosphate $(0.1 \mathrm{~mol} / \mathrm{l}), 0.1 \mathrm{ml}$ buffer $\mathrm{pH} 7.0$ containing citric acid, $(0.05 \mathrm{~mol} / \mathrm{l})$, potassium phosphate $(0.1 \mathrm{~mol} / 1$ in phosphate), $0.6 \mathrm{ml} \mathrm{BSA}(4.2 \mathrm{~g} / 1)$ and $0.05 \mathrm{ml}$ stearic acid $(2.0 \mu \mathrm{Ci}$; $1.06 \times 10^{-4} \mathrm{M}$ final concentration) bound to BSA were mixed together and were preincubated for $5 \mathrm{~min}$ at $37^{\circ}$ (R. Jeffcoat, personal communication). The reaction was initiated by addition of microsomal preparation containing approximately $1.5 \mathrm{mg}$ protein, and was terminated after $6 \mathrm{~min}$ at $37^{\circ}$ by addition of $2.0 \mathrm{ml}$ potassium hydroxide $(0.5 \mathrm{~mol} / \mathrm{l})$.

Methyl esters of the fatty acids were prepared as described elsewhere (Olpin \& Bates, 1982). These were then separated and the distribution of radioactivity between fatty acids 18:0 and 18:1 measured on a Pye series 204 gas-liquid chromatograph, operating at $150^{\circ}$ with a carrier gas of carbon dioxide in argon ( $50 \mathrm{ml} / \mathrm{l})$ through a $1.5 \mathrm{~m} \times 4 \mathrm{~mm}$ column of $100 \mathrm{~g}$ EGSS-X/kg Gas Chrom Q (100-120 mesh) (prepared by Pye Unicam Ltd) with a stream splitter, one side of which was connected to a Panax Radiogas detector system and the other to a flame-ionization detector.

Protein determination. The protein content of mitochondrial preparations was estimated by the method of Lowry et al. (1951) after precipitation with trichloroacetic acid (final concentration $50 \mathrm{~g} / \mathrm{l})$. Protein in the microsomal preparations was estimated by the Biuret procedure (Gornall et al. 1949) on samples dissolved in Triton X-100, with a blank correction for turbidity. 


\section{RESULTS}

\section{$\mathrm{O}_{2}$ utilization by mitochondria}

The effects of riboflavin deficiency on rates of hepatic mitochondrial $\mathrm{O}_{2}$ consumption for groups of rats given three diets of different lipid composition, are shown in Table 1. For all three groups, with hexanoate as substrate, there were highly-significant reductions in the rate of $\mathrm{O}_{2}$ consumption in the mitochondria from deficient animals, to approximately $50 \%$ of the values observed for the pair-fed controls. The picture was similar with palmitoylL-carnitine as substrate, where the mean deficient values were approximately $44 \%$ of the mean control values, and the extent of reduction was similar, or slightly greater, with stearoyl-L-carnitine ( $39 \%$ of control values); oleoyl-L-carnitine ( $37 \%$ of control values) and linoleoyl-L-carnitine ( $32 \%$ of control values). The effect of riboflavin deficiency on glutamate oxidation was relatively small, the deficient mitochondria attaining $79 \%$ of the control activities over all, and falling significantly below the controls only in the group given the maize-oil diet. There were no consistent differences in $\mathrm{O}_{2}$ consumption rates attributable to the different lipid contents of the diets, for either the deficient or the control sets.

\section{Acyl COA dehydrogenase (EC 1.3.99.3)}

Riboflavin deficiency resulted in a significant reduction in $V_{\max }(\mathrm{PMS})$ for this enzyme for all three diets of different lipid contents (Table 2), and the magnitude of the reduction was similar to the reduction in $\mathrm{O}_{2}$ utilization by intact mitochondria, with palmitoyl carnitine as substrate. The apparent $K_{m}$ (PMS) was also reduced in the mictochondria from the deficient animals: this attained significance for those receiving the $200 \mathrm{~g}$ arachis-oil $/ \mathrm{kg}$ diet $(P<0.05)$ and the $30 \mathrm{~g}$ maize-oil $/ \mathrm{kg} \operatorname{diet}(P<0.001)$.

\section{Microsomal enzyme activities}

Despite a highly-significant reduction in NADPH-cytochrome $c$ reductase $(E C$ 1.6.2.4) activity in the microsomes of riboflavin-deficient animals (Table 3) to $55 \%$ of the mean pair-fed control value, and a similar reduction in total flavin concentration in the microsomal fraction, there was no detectable change in the NADH cytochrome $b_{5}$ reductase $(E C$ 1.6.2.2) activity (Table 3). Likewise, acyl CoA $(\triangle 9)$ desaturase (EC 1.14.99.5) activity in the microsomes was apparently unaffected by riboflavin deficiency (Table 4 ).

\section{DISCUSSION}

A reduction of $50-70 \%$ in rates of oxidation of fatty acid substrates and of $V_{\max }$ for fatty acyl CoA dehydrogenase activity in the deficient animals is consistent with the observations of Hoppel et al. (1979), and confirms that these effects of riboflavin deficiency are still evident when the control animals receive diets identical with those fed to the deficient groups, apart from their riboflavin content, and are pair-fed to control the effects of inanition. Likewise, it is clear that the oxidation of fatty acids is impaired to a greater extent than that of glutamate. The apparent change in $K_{m}$ with respect to phenazine methosulphate in the dehydrogenase assay is puzzling; it suggests that the affinity for the electron acceptor is increased in the deficient animals. However, it is not known whether a similar result would be obtained with the natural electron acceptor, nor whether this observation has any physiological significance.

The reduction in oxidation of linoleoyl carnitine was at least as great, and possibly greater, than that of the other fatty acid substrates, which is consistent with the observed accumulation of fatty acid 18:2 in tissue phospholipids and triglycerides (Olpin \& Bates, 1982).

The microsomal studies have demonstrated that despite a considerable reduction in NADPH-cytochrome $c$ reductase activity in deficient animals, which is consistent with the 


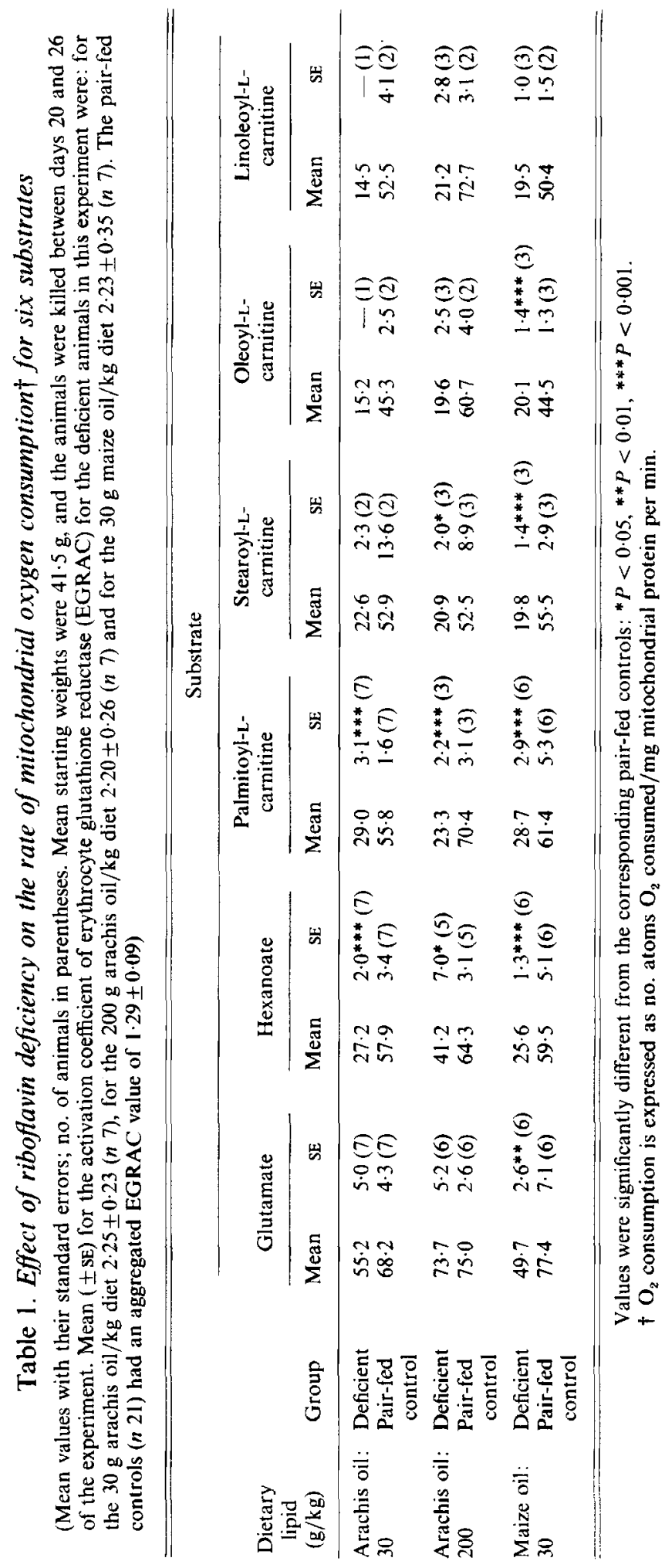


Table 2. Effects of riboflavin deficiency on the activity of acyl-CoA dehydrogenases (EC 1.3.99.3)

(Mean values with their standard errors; no. of animals in parentheses. Mean starting weights were $46.0 \mathrm{~g}$, and the animals were killed between days 27 and 34 of the experiment. $V_{\max }$ [phenazine methosulphate] is the activity extrapolated to infinite concentration of phenazine methosulphate: see MATERIALS AND METHODS, using palmitoyl-CoA as substrate)

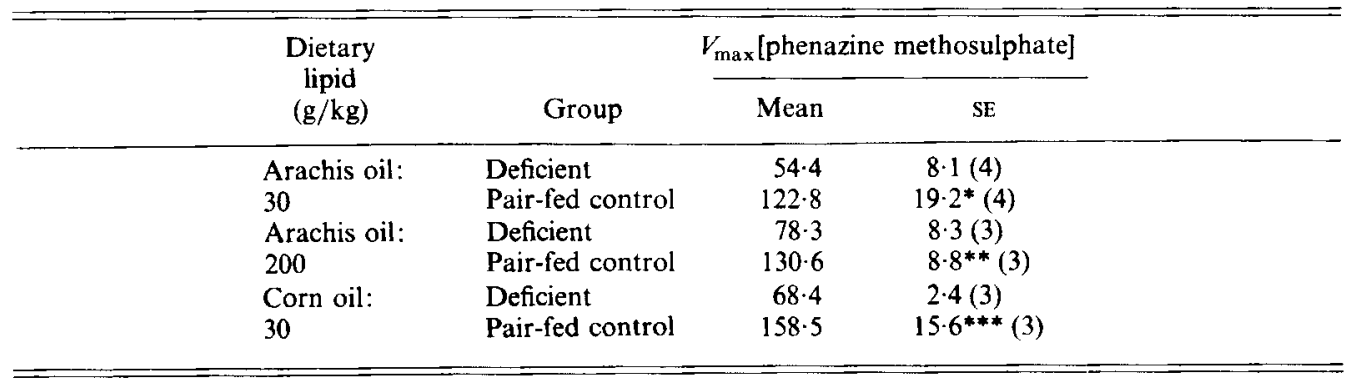

Values were significantly different from the corresponding pair-fed controls: ${ }^{*} P<0.02,{ }^{* *} P<0.01$, *** $P<0.001$.

A similar reduction in $V_{\max }$ [phenazine methosulphate] in deficient animals as compared to pair-fed controls was obtained using stearoyl-CoA as substrate, under otherwise identical conditions.

observations of Shargel \& Mazel (1973), of Patel \& Pawar (1974) and of Taniguchi (1980) in rats and of Yang (1974) in mice, together with a corresponding reduction in total microsomal-flavin content, there was nevertheless no detectable reduction in NADHcytochrome $b_{5}$ reductase activity, (a flavoprotein which channels electrons into the fatty acid desaturase pathway; Holloway, 1971; Shimakata et al. 1972), as measured by reduction of ferricyanide (Mihara \& Sato, 1978). Likewise, the activity of acyl CoA $\Delta 9$ desaturase was not diminished in the deficient animals. These conclusions differ from those of Okayasu et al. (1977), but it is difficult to make meaningful comparisons since their experimental conditions were very different, and no statistical analyses were recorded.

The lack of an effect on the desaturase is consistent with the fact that no flavin-dependent process beyond cytochrome $b_{5}$ reductase has yet been identified in the desaturase pathway. Some preliminary attempts to study $\Delta 6$ desaturase activity have not yet yielded conclusive results however, and it remains possible that the conversion of 18:2 to 20:4 may be specifically impaired. An impairment in this conversion was not, however, detected by Williams et al. (1967) during recovery from combined riboflavin and essential fatty acid deficiency in the rat, and at present, the simplest explanation for the relative accumulation of fatty acid 18:2 and reduction in 20:4 levels in tissues of deficient animals would appear to be an over-all reduction in $\beta$-oxidation, resulting in the accumulation of those fatty acids which are present in dietary lipids, but which are not synthesized de novo in the body.

Whether these effects of severe riboflavin deficiency on fatty acid oxidation in rats are relevant to the pathology of riboflavin deficiency in human populations is not yet known. Suckling rats derive a higher proportion of their energy from lipids than do foetal or adult animals (Drahota et al. 1965-6; Yeh \& Zee, 1979), and it is thus possible that human babies may be especially vulnerable to this metabolic lesion during their first few months of life. 


ริ

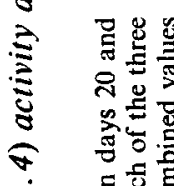

ㄴ.

‥

-

过 总嵒的

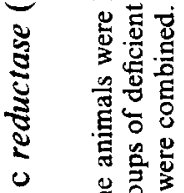

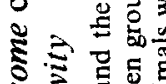

方

ปั

$\Sigma \sim$ 过

20

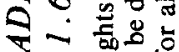

之u

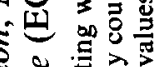

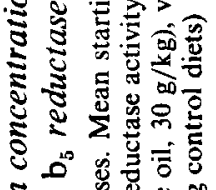

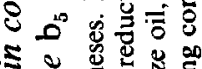

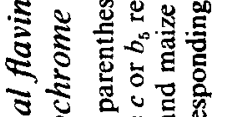

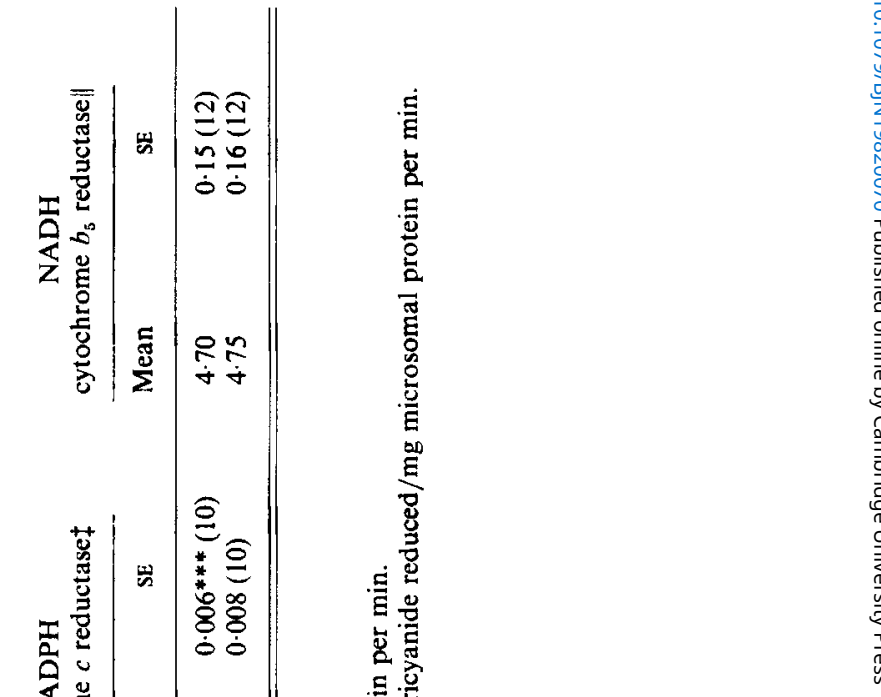

응

정

츨

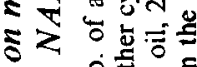

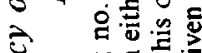

妾

\&

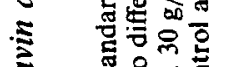

है कै

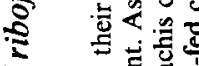

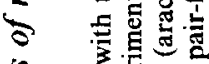

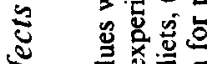

冬

i

늘 टेष

Z

竞

点

$\frac{2}{\circ} \frac{2}{0}$

혀음 
Table 4. Effect of riboflavin deficiency on acyl CoA $(\Delta 9)$ desaturase (EC 1.14.99.5) activity

(Mean values with their standard errors; no. of assays in parentheses. The diets contained maize oil ( 30 $\mathrm{g} / \mathrm{kg}$ ) and the animals (whose mean starting weight was $50.2 \mathrm{~g}$ ) were killed between days 28 and 33 . Each assay was carried out on the microsomes obtained from two rats after combining equal weights of liver from each animal. The severity of the riboflavin deficiency, and responses of the controls, were similar to those of corresponding groups of animals described in Table 2, and in the accompanying paper (Olpin \& Bates, 1982))

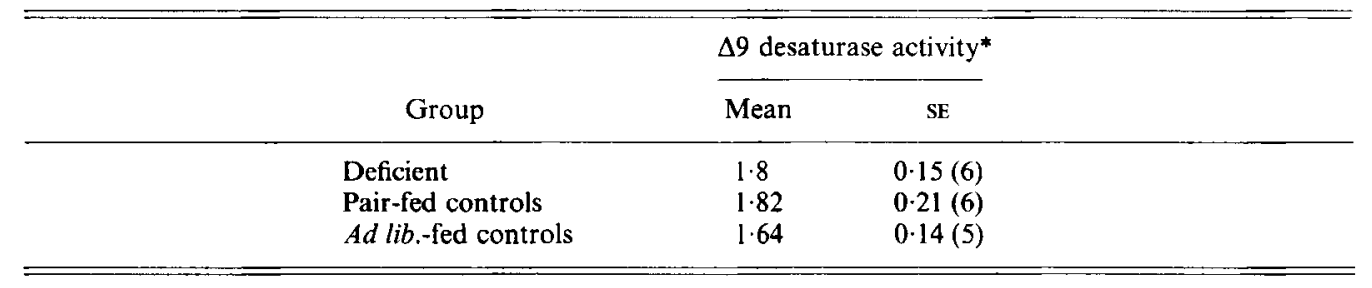

* nmol 18:1 produced/mg protein per min.

\section{S.E.O. was supported by a Medical Research Council Research Studentship.}

\section{REFERENCES}

Chance, B. \& Williams, G. R. (1955). J. biol. Chem. 217, 409.

Drahota, Z., Hahn, P. \& Honova, E. (1965-6). Biol. Neonat. 9, 124.

Gornall, A. G., Bardawill, C. J. \& David, M. M. (1949). J. biol. Chem. 177, 751.

Hauge, J. G. (1956). J. Am. Chem. Soc. 78, 5266.

Holloway, P. W. (1971). Biochemistry, Easton 10, 1556.

Hoppel, C. L., DiMarco, J. P. \& Tandler, B. (1979). J. biol. Chem. 254, 4164.

Hoppel, C. L. \& Tandler, B. (1975). J. Nutr. 105, 562.

Hoskins, D. D. (1969). Meth. Enzym. 14, 110.

Lowry, O. H., Rosebrough, N. J., Farr, A. L. \& Randall, R. J. (1951). J. biol. Chem. 193, 265.

Mihara, K. \& Sato, R. (1978). Meth. Enzym. 52, 102.

Okayasu, T., Kameda, K., Ono, T. \& Imai, Y. (1977). Biochim. biophys. Acta 489, 397.

Olpin, S. E. \& Bates, C. J. (1982). Br. J. Nutr. 47, 577.

Patel, J. M. \& Pawar, S. S. (1974). Biochem. Pharmac. 23, 1467.

Philips, A. V. \& Langdon, R. G. (1962). J. biol. Chem. 237, 2652.

Shargel, L. \& Mazel, P. (1973). Biochem. Pharmac. 22, 2365.

Shimakata, T., Mihara, K. \& Sato, R. (1972). J. Biochem., Tokyo 72, 1163.

Taniguchi, M. (1980). J. Nutr. Sci. Vitam. 26, 401.

Williams, M. A., McIntosh, D. J., Hincenbergs, I. \& Tamai, K. T. (1967). Biochim. Biophys. Acta 137, 388.

Yang, C. S. (1974). Archs. Biochem. Biophys. 160, 623.

Yeh, Y.-Y. \& Zee, P. (1979). Archs. Biochem. Biophys. 199, 560. 